\title{
Mutator specificity of Escherichia coli alkB117 allele
}

\author{
Jadwiga Nieminuszczy, Celina Janion and Elżbieta Grzesiuk ${ }^{\bowtie}$ \\ Institute of Biochemistry and Biophysics, Polish Academy of Sciences, Warszawa, Poland; \\ 『e-mail: elag@ibb.waw.pl
}

Received: 16 February, 2006; revised: 17 March, 2006; accepted: 05 May, 2006

available on-line: 29 May, 2006

\begin{abstract}
The Escherichia coli AlkB protein encoded by alkB gene was recently found to repair cytotoxic DNA lesions 1-methyladenine (1-meA) and 3-methylcytosine (3-meC) by using a novel iron-catalysed oxidative demethylation mechanism that protects the cell from the toxic effects of methylating agents. Mutation in alkB results in increased sensitivity to MMS and elevated level of MMSinduced mutations. The aim of this study was to analyse the mutational specificity of alkB117 in a system developed by J.H. Miller involving two sets of E. coli lacZ mutants, CC101-106 allowing the identification of base pair substitutions, and CC107-CC111 indicating frameshift mutations. Of the six possible base substitutions, the presence of alkB117 allele led to an increased level of GC $\rightarrow$ AT transitions and GC $\rightarrow$ TA and AT $\rightarrow$ TA transversions. After MMS treatment the level of GC $\rightarrow$ AT transitions increased the most, 22-fold. Among frameshift mutations, the most numerous were $-\mathbf{2 C G},-1 G$, and $-\mathbf{1 A}$ deletions and $+\mathbf{1 G}$ insertion. MMS treatment appreciably increased all of the above types of frameshifts, with additional appearance of the $+1 \mathrm{~A}$ insertion.
\end{abstract}

Keywords: E. coli, alkB117, MMS, mutational specificity, lacZ $\rightarrow \mathrm{Lac}^{+}$reversion

\section{INTRODUCTION}

Alkylating agents introducing a variety of lesions into DNA are wide spread in the environment (Taverna \& Sedgwick, 1996; Sedgwick, 2004). To protect their DNA, organisms possess mechanisms that abolish the harmful effects of alkylanes. In Escherichia coli alkylating agents induce so called adaptive response involving the $a d a, a l k B, a l k A$ and aidB genes (Samson \& Cairns, 1977). The alkB-encoded AlkB protein is a dioxygenase that oxidatively demethylates $1 \mathrm{meA}$ and $3 \mathrm{meC}$ in DNA in a reaction that involves $\alpha$-ketoglutarate, $\mathrm{O}_{2}$, and $\mathrm{Fe}(\mathrm{II})$ (Trewick et al., 2002; Begley \& Samson, 2003; Falnes \& Rognes, 2003).

MMS (methyl methanesulfonate) is an $\mathrm{S}_{\mathrm{N}} 2$ type alkylating agent which predominantly methylates nitrogen in DNA purines generating $N^{7}$-methylguanine (7-meG), $N^{3}$-methyladenine (3-meA), $N^{7}-$ methyladenine (7-meA), $N^{1}$-methyladenine (1-meA), and $\mathrm{O}^{6}$-methylguanine $\left(\mathrm{O}^{6}\right.$-meG) (Grzesiuk, 1998). Enzymatic or spontaneous loss of 3-meA, 3-meG and 7-meG leads to the formation of apurinic sites which may induce $\mathrm{AT} \rightarrow \mathrm{TA}$ or $\mathrm{GC} \rightarrow \mathrm{TA}$ transversions involving polymerase $\mathrm{V}$-directed translesion synthesis (Grzesiuk \& Janion, 1994; Fuchs et al., 2004).

Damage to alkB greatly increases the sensitivity of bacteria to MMS, diminishes the ability to reactivate MMS-treated single-stranded phage DNA (Dinglay et al., 2000) and markedly increases MMSinduced mutagenesis in E. coli AB1157 cells (Kataoka et al., 1983; Nieminuszczy et al., 2006).

The aim of this study was to analyse the mutational specificity of the alkB117 mutation in a system developed by Cupples and Miller (1989) and Cupples et al. (1990). This system includes a set of eleven lacZ mutants of E. coli CC101-CC111, and allows for the identification of all six types of base substitutions and five types of frameshift mutations.

\section{MATERIALS AND METHODS}

Bacterial strains. The bacteria used in this study were E. coli CC101-CC111 strains constructed in Miller's laboratory (Cupples \& Miller, 1989; Cup- 
ples et al., 1990). Strains CC101-CC106 contain base substitution mutations in the lacZ gene (phenothype $\mathrm{Lac}^{-}$). Reversion of these mutations leads to the ability to metabolise lactose (phenotype $\mathrm{Lac}^{+}$) (Borden et al., 2002). In strains CC107-CC111 the altered sequences are in runs of six or seven repeated base pairs creating frameshift mutations. Reversion to $\mathrm{Lac}^{+}$can occur by addition or deletion of the altered sequences and recovery of the proper reading frame for $\beta$-galactosidase synthesis (Cupples et al., 1990). A detailed description of the CC101-CC111 strains and the pathways of $\mathrm{Lac}^{+}$reversions is shown in Fig. 1 .

The alkB117 gene was introduced into the CC101-CC111 strains by P1-mediated transduction (Miller, 1972). The donor strain for alkB117::Tn3 was BS87 (Sedgwick, 1992). The transductants were selected on LB plates containing carbenicillin $(50 \mu \mathrm{g} / \mathrm{ml})$, and then their desired phenotype was ascertained.

Mutational specificity assay. The appropriate bacteria (CC101-CC111 and their alkB117 deriva- tives) were grown overnight at $37^{\circ} \mathrm{C}$ with shaking in minimal C-salts medium consisting of C-salts (Vogel \& Bonner, 1956) supplemented with $0.5 \%$ glucose, $0.2 \%$ casamino acids and $2 \mu \mathrm{g} / \mathrm{ml}$ thiamine. When cultures reached $(2-4) \times 10^{8}$ cells $/ \mathrm{ml}$ they were treated with $0.17 \%$ (20 mM) MMS for $15 \mathrm{~min}$, centrifuged, washed twice, and resuspended in the same volume of C-salts medium without glucose. Aliquots of $0.1 \mathrm{ml}$ diluted to $10^{-6}$ were plated on LB-plates and of $0.1 \mathrm{ml}$ on C-salts plates enriched with $0.5 \%$ lactose and $2 \mu \mathrm{g} / \mathrm{ml}$ thiamine. Plates were incubated at $37^{\circ} \mathrm{C}$ and screened after one day for viable cells, or after two days for $\mathrm{Lac}^{+}$revertants. Only the $\mathrm{Lac}^{+}$ revertants give readily visible colonies on selective plates with lactose as the only source of carbon.

Reversion frequencies for each $\mathrm{Lac}^{-}$strain were calculated by dividing the number of $\mathrm{Lac}^{+}$revertants by the total number of viable cells. For each strain experiments were repeated 5 times and standard deviations $( \pm$ S.D.) were calculated.

(A)

$\beta$-galactosidase

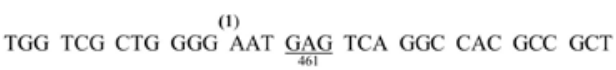

AAT CAC GAC GCG GTG TAT CGC TGG ATC AAA TCT

CTG GAT CCT TCC CGC CCG GTG CAG TAT GAA GGC

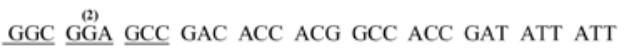

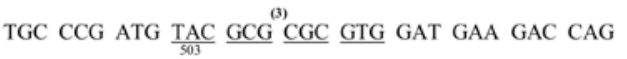

CCC TTC CCG GCT GTG CCG AAA TGG TCC $\underline{\text { ATC }}$ AAA

AAA $\stackrel{(4)}{\text { TGG CTT }}$

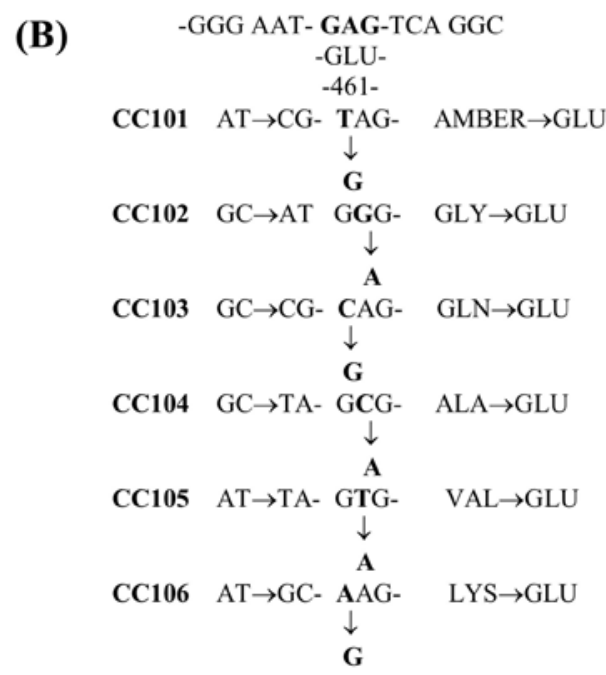

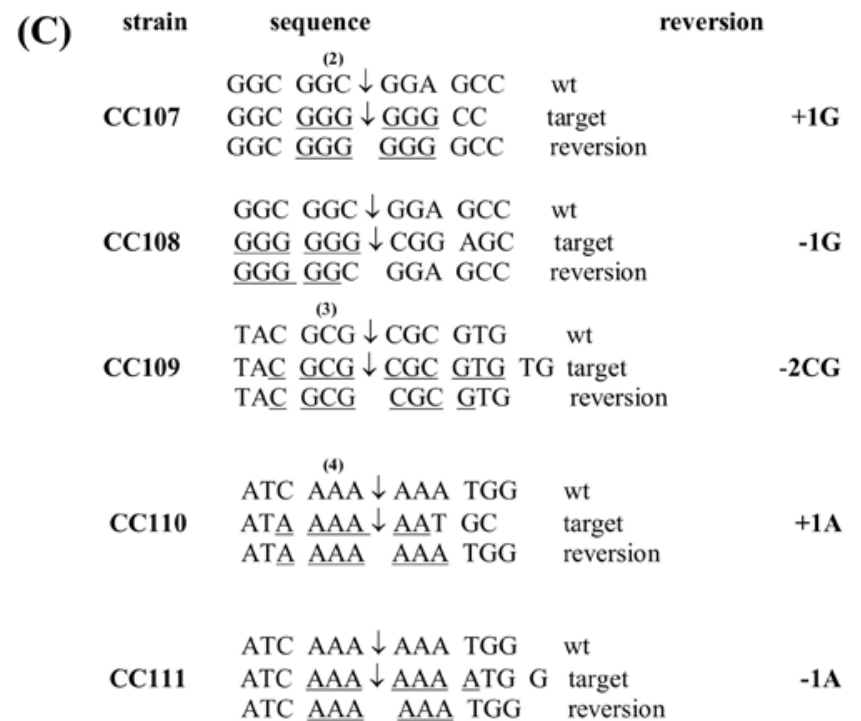

Figure 1. Location of target sites in lacZ gene.

(A) The portion of the lacZ gene containing the following sites: (1) Glu-461 codon that was altered to yield strains CC101-CC106 for detecting base substitutions (Cupples \& Miller, 1989); (2), (3) and (4) sequences that were altered to yield strains for detecting frameshift mutations (Cupples et al., 1990): CC107 and CC108 at site (2), CC109 at site (3) and CC110 and CC111 at site (4). (B) Base substitutions required to restore codon 461 to GAG in CC101-CC106 strains. (C) Frameshift mutations required to restore the correct amino-acid sequence in CC107-CC111 strains. 
Plate test for quick screening of alkB mutants. An aliquot of $0.1 \mathrm{ml}$ of overnight culture in LB was added to $5 \mathrm{ml}$ of $0.5 \%$ top agar and poured onto LB plate. Blotting paper disc (5 $\mathrm{mm}$ diameter) with $2 \mu \mathrm{l}$ of MMS were then placed on the plate surface and incubated for one day at $37^{\circ} \mathrm{C}$. The zones of bacterial growth inhibition were measured.

\section{RESULTS AND DISCUSSION}

We have shown that in the $\operatorname{argE3} \rightarrow \mathrm{Arg}^{+}$reversion system MMS induces an extremely high level of $\mathrm{Arg}^{+}$revertants in AB1157 strains mutated in the alkB gene and that these revertants are mainly $\mathrm{GC} \rightarrow \mathrm{AT}$ transitions and $\mathrm{AT} \rightarrow \mathrm{TA}$ transversions (Nieminuszczy et al., 2006).

Here, we used lacZ $\rightarrow \mathrm{Lac}^{+}$reversion to estimate the specificity of alkB117 mutation. The alkB117 allele was introduced into a set of E. coli CC101CC111 strains. The presence of alkB117 was proved by plate test showing an increased sensitivity of CC101-CC111 alkB117 bacteria to MMS.

The CC101-CC111 strains by themselves showed a very low level of spontaneous $\mathrm{Lac}^{+}$revertants. These revertants arose by base substitutions: $\mathrm{GC} \rightarrow \mathrm{TA}$ in CC104 strain $\left(0.21 \mathrm{Lac}^{+}\right.$revertants per $10^{8}$ cells) and $\mathrm{AT} \rightarrow \mathrm{TA}$ in CC105 strain $\left(0.19 \mathrm{Lac}^{+}\right.$ revertants per $10^{8}$ cells) or by frameshifts: +1G (CC 107), -1G (CC108), -2CG (CC109), and -1A (CC111); respective mutation frequencies were 24.3, 16.1, 38.6, and $12.1 \mathrm{Lac}^{+}$revertants per $10^{8}$ cells.

The presence of the alkB117 mutation increased the frequency and variety of spontaneous $\mathrm{Lac}^{+}$revertants (Figs. 2 and 3). The most numerous among base substitutions were GC $\rightarrow$ AT transitions (1.25 $\mathrm{Lac}^{+}$revertants per $10^{8}$ cells). Also a new class of base substitutions, namely GC $\rightarrow$ TA transversions appeared in the CC104 alkB117 strain. The frequency of this class of mutations was $0.61 \mathrm{Lac}^{+}$revertants per $10^{8}$ cells.

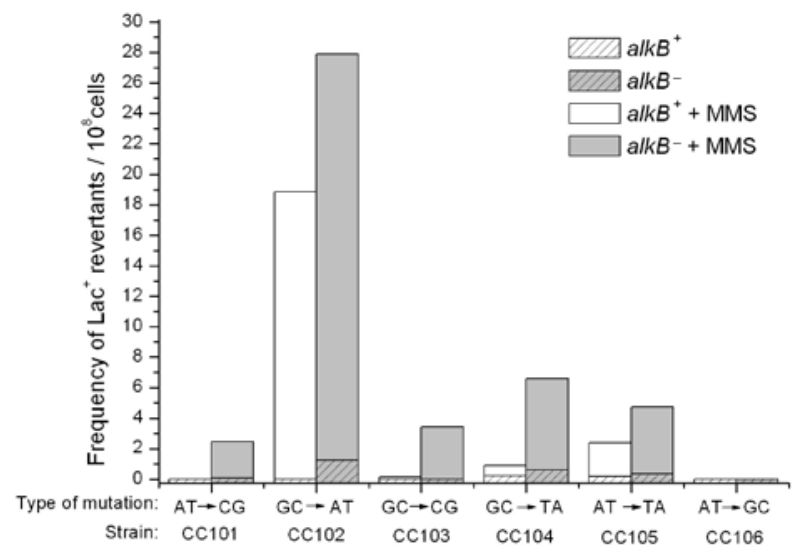

Figure 2. The specificity of spontaneous and MMS-induced base substitution mutations in CC101-CC106 wt $\left(a l k B^{+}\right)$strains and their alkB117 $\left(\right.$alkB $\left.{ }^{-}\right)$derivatives.

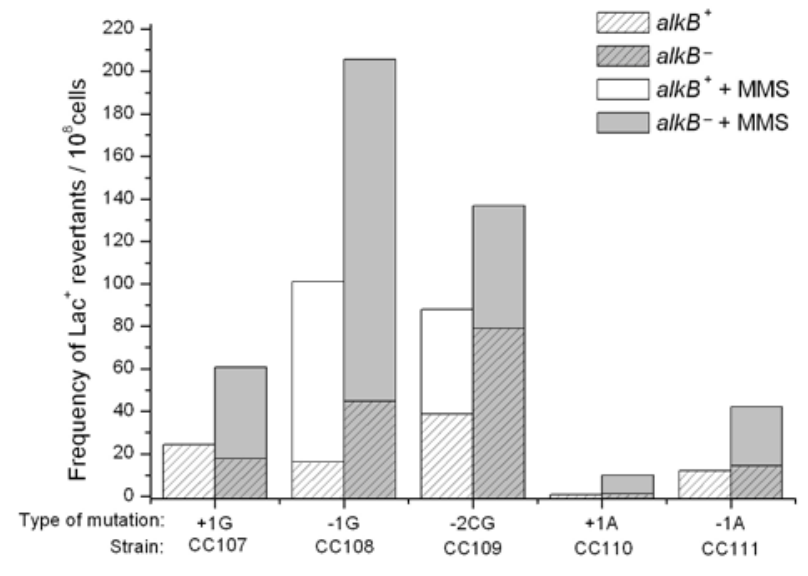

Figure 3. The specificity of spontaneous and MMS-induced frameshift mutations in CC107-CC111 wt $\left(\right.$ alkB $\left.{ }^{+}\right)$ strains and their alkB117 (alkB $\left.{ }^{-}\right)$derivatives.

Introduction of alkB117 to the CC107-CC111 strains measuring frameshift mutations led to increased level of two types of frameshifts, $-1 G$ (44.6 $\mathrm{Lac}^{+}$revertants per $10^{8}$ cells, which is 3-fold higher in comparison to CC108 wt) and -2CG (79.0 Lac ${ }^{+}$revertants per $10^{8}$ cells, which is 2 -fold higher in comparison to CC109 wt) (Fig. 3).

In the CC101-CC106 wt strains MMS induces mainly GC $\rightarrow$ AT transitions $\left(27.9 \mathrm{Lac}^{+}\right.$revertants per $10^{8}$ cells) and, to a lesser degree, $\mathrm{AT} \rightarrow \mathrm{TA}$ transversions (4.7 $\mathrm{Lac}^{+}$revertants per $10^{8}$ cells) (Fig. 2); among the CC107-CC111 wt strains, MMS induces first of all -2CG frameshifts (in CC109, $79.0 \mathrm{Lac}^{+}$ revertants per $10^{8}$ cells) and $-1 \mathrm{G}$ (in CC108, 44.6 $\mathrm{Lac}^{+}$revertants per $10^{8}$ cells). The respective values for +1G (CC107), $-1 \mathrm{~A}$ (CC111), and +1A (CC110) were $17.8,14.3$, and $2.1 \mathrm{Lac}^{+}$revertants per $10^{8}$ cells (Fig. 3).

In the alkB117 derivatives of the CC101CC106 strains MMS treatment led to an induction of 5 out of 6 base substitutions with noticeable prevailing of mutations arising by $\mathrm{GC} \rightarrow \mathrm{AT}$ transitions measured in the CC102 alkB117 strain $\left(27.9 \mathrm{Lac}^{+}\right.$ revertants per $10^{8}$ cells) (Fig. 2). The highest mutator effect of alkB117 after MMS treatment was noted for frameshift mutations. Compared to the CC107CC111 wt strains the level of +1G, -1G, -2CG, +1A, and $-1 \mathrm{~A}$ increased 3.4-, 4.6-, 1.7-, 5.0-, and 3.0-fold, respectively (Fig. 3).

The specificity of the alkB117 mutation has been already measured by Dinglay and co-workers (2000) and Nieminuszczy and co-workers (2006). The first group used the Miller's strains but only those identifying base substitutions (CC101-CC106), the second one used T4 mutants. The phage system identifies only two base substitutions and in this respect the present results are in agreement with the previous ones. However, base substitutions are a minor group of MMS-induced alkB-specific mutations. We found that most of these mutations arise 
by all types of frameshift measured, but especially the $-1 G$ and $-2 C G$ deletions.

It is worth noticing that of the two alkB mutants available, HK82 (alkB22) and BS87 (alkB117), HK82 has shown a 10-fold higher level of MMSinduced $\operatorname{argE3} \rightarrow \mathrm{Arg}^{+}$revertants compared to BS87 (Nieminuszczy et al., 2006). Our unpublished results suggest the presence of an additional mutation in HK82 strain. This could explain the differences in the specificity of the alkB mutation in HK82 (Delaney \& Essigmann, 2004) and assayed here, in the BS87 strain.

\section{CONCLUSIONS}

Using the $\operatorname{argE3} \rightarrow \mathrm{Arg}^{+}$reversion system we have found that mutation in alkB gene followed by an inability to repair $1 \mathrm{meA} / 3 \mathrm{meC}$ in DNA greatly increases the mutagenic potency of MMS. Here we found that mutations specific for alkB117 are due to $\mathrm{GC} \rightarrow \mathrm{AT}, \mathrm{GC} \rightarrow \mathrm{TA}$, and $\mathrm{AT} \rightarrow \mathrm{TA}$ base substitutions, and $-1 G$ and $-2 C G$ frameshifts. These results indicate that $A$ and $C$ residues could be the target of MMS attack.

\section{Acknowledgement}

This work was supported by the State Committee for Scientific Research, Poland, grant 0420/ P04/2004/27.

\section{REFERENCES}

Begley TJ, Samson LD (2003) Trends Biochem Sci 28: 2-5.

Borden A, O'Grady PI, Vandewiele D, Fernandez de Henestrosa AR, Lawrence CW, Woodgate R (2002) J Bacteriol 184: 2674-2681.

Cupples CG, Miller JH (1989) Proc Natl Acad Sci USA 86: 5345-5349.

Cupples CG, Cabrera M, Cruz C, Miller JH (1990) Genetics 125: $275-280$.

Delaney JC, Essigmann JM (2004) Proc Natl Acad Sci USA 101: 14051-14056.

Dinglay S, Trewick SC, Lindahl T, Sedgwick B (2000) Genes Develop 14: 2097-2105.

Falnes PO, Rognes T (2003) Res Microbiol 154: 531-538.

Fuchs RP, Fujii S, Wagner J (2004) Adv Prot Chem 69: 229264.

Grzesiuk E (1998) Acta Biochim Polon 45: 523-533.

Grzesiuk E, Janion C (1994) Mol Gen Genet 245: 486-492.

Kataoka H, Yamamoto Y, Sekiguchi M (1983) J Bacteriol 153: 1301-1307.

Miller JH (1972) Experiments in Molecular Genetics, pp. 215217, Cold Spring Harbor Laboratory, New York.

Nieminuszczy J, Sikora A, Wrzesinski M, Janion C, Grzesiuk E (2006) DNA Repair 5: 181-188.

Samson L, Cairns J (1977) Nature 267: 281-283.

Sedgwick B (1992) Cancer Res 52: 3693-3697.

Sedgwick B (2004) Nat Rev Mol Cell Biol 5: 148-157.

Taverna P, Sedgwick B (1996) J Bacteriol 178: 5105-5111.

Trewick SC, Henshaw TF, Hausinger RP, Lindahl T, Sedgwick B (2002) Nature 419: 174-178.

Vogel HJ, Bonner DM (1956) J Biol Chem 218: 97-106. 